
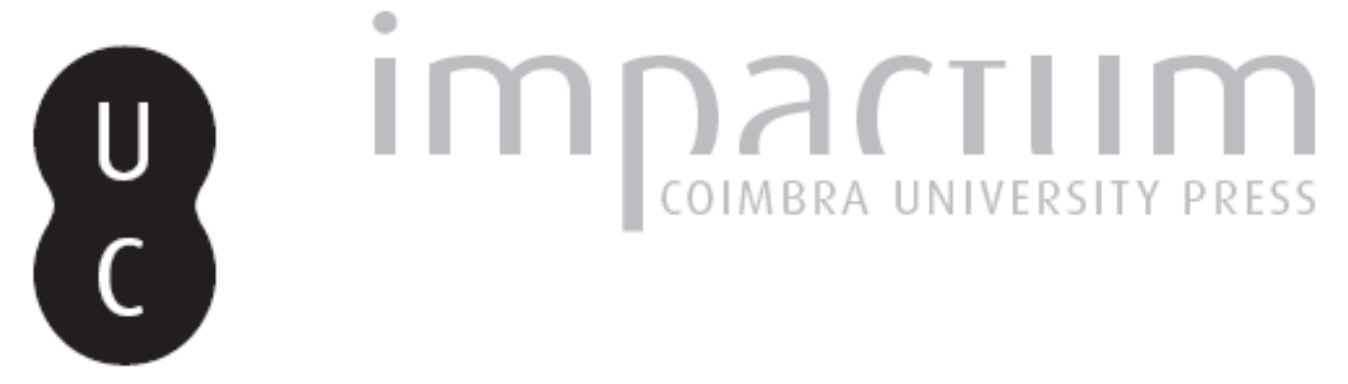

\title{
O impacto da perícia médico-legal na decisão judicial nos casos de abuso sexual de crianças: estudo preliminar
}

Autor(es): $\quad$ Jardim, Patrícia; Matos, Eduarda; Magalhães, Teresa

Publicado por: Imprensa da Universidade de Coimbra

URL persistente:

URI:http://hdl.handle.net/10316.2/33215

DOI:

DOI:http://dx.doi.org/10.14195/1647-8630_22_2

Accessed : $\quad$ 26-Apr-2023 10:30:44

A navegação consulta e descarregamento dos títulos inseridos nas Bibliotecas Digitais UC Digitalis, UC Pombalina e UC Impactum, pressupõem a aceitação plena e sem reservas dos Termos e Condições de Uso destas Bibliotecas Digitais, disponíveis em https://digitalis.uc.pt/pt-pt/termos.

Conforme exposto nos referidos Termos e Condições de Uso, o descarregamento de títulos de acesso restrito requer uma licença válida de autorização devendo o utilizador aceder ao(s) documento(s) a partir de um endereço de IP da instituição detentora da supramencionada licença.

Ao utilizador é apenas permitido o descarregamento para uso pessoal, pelo que o emprego do(s) título(s) descarregado(s) para outro fim, designadamente comercial, carece de autorização do respetivo autor ou editor da obra.

Na medida em que todas as obras da UC Digitalis se encontram protegidas pelo Código do Direito de Autor e Direitos Conexos e demais legislação aplicável, toda a cópia, parcial ou total, deste documento, nos casos em que é legalmente admitida, deverá conter ou fazer-se acompanhar por este aviso.

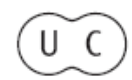




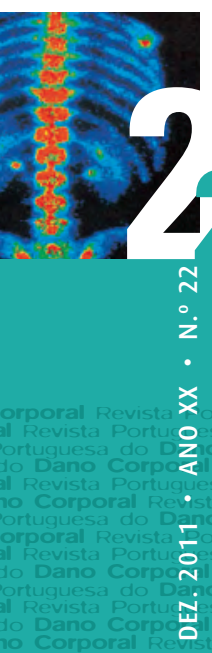

$$
\text { REVISTA PORT U/GUESA }
$$

do
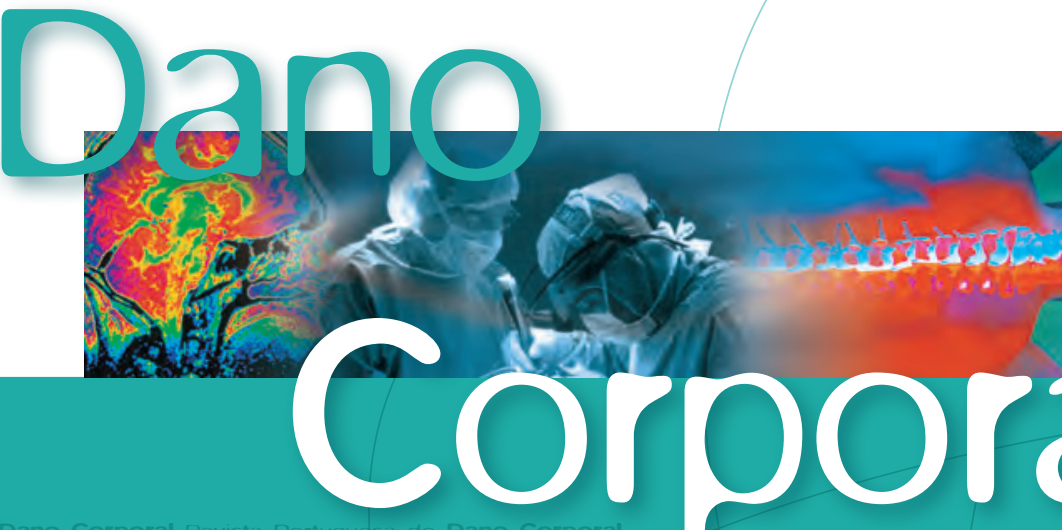

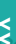

Oesa do Dano Corporal Revista Portuguesa do Dano Corporal

Zo Corporal Revista Portuguesa do Dano Corporal Revista Portuguesa do Dano Corporal

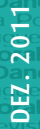

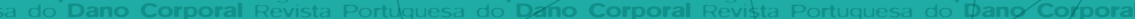

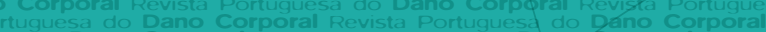

Revista Portuguesa do Dano Corporal Revista Rortuguesa do Dano Corporal
Ro Corporal Revista Portuguesa do Dano Corpgral Revista Portuguesa do Dano Corporal

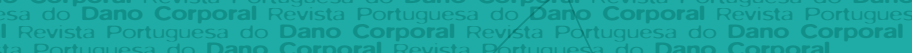




\title{
0 impacto da perícia médico-legal na decisão judicial nos casos de abuso sexual de crianças. Estudo preliminar
}

\author{
Patrícia Jardim ${ }^{(1,2,3)}$, Eduarda Matos ${ }^{(4)}$, Teresa Magalhães ${ }^{(1,4)}$
}

\section{INTRODUÇÃO}

Muitos estudos nacionais e internacionais têm vindo a ser desenvolvidos na área dos crimes de natureza sexual, particularmente sobre os praticados contra crianças. Estes têm revelado elevada prevalência e incidência do fenómeno, que se apresenta transversal a todos os países do mundo, culturas, e estratos sociais e económicos (Finkelhor, 1994; Pereda e col., 2009a; Pereda e col., 2009b). Por outro lado, a estas práticas associam-se: (a) baixas taxas de revelação por parte das vítimas (London e col., 2005; Nagel e col., 1996; Goddman-Brown e col., 2003); (b) reduzido número de denúncias pelas pessoas que suspeitam dos mesmos (Ribeiro \& Magalhães, 2010); (c) graves consequências para as crianças e suas famílias, a curto, médio e longo prazo (Swanston e col., 2003; Briere \& Elliot, 2003). Em conjunto, todos estes aspetos justificam que a Organização Mundial de Saúde (WHO) considere esta problemática como uma "silent health emergency" de relevância internacional, no âmbito da saúde pública (WHO, 2004).

Importa, assim, que em todos os países se desenvolva mais investigação nesta área, nos diversos domínios da sua intervenção e, sobretudo, articulando saberes e práticas, designadamente no que à intervenção médico-legal e forense, conjugada com a intervenção judicial, diz respeito.

\footnotetext{
Instituto Nacional de Medicina Legal, I.P. - Delegação do Norte

CENCIFOR - Centro de Ciências Forenses, Portugal

Faculdade de Medicina da Universidade do Porto

Instituto de Ciências Biomédicas "Abel Salazar" da Universidade do Porto
} 


\subsection{A problemática dos conceitos}

Uma das dificuldades no estudo deste tema consiste no facto de na literatura internacional, e no contexto legal específico de cada país, serem utilizados diferentes conceitos para referir as agressões de natureza sexual contra crianças, estando estes relacionados com o meio cultural em que as vítimas se encontram inseridas, com as diferentes definições legais destes tipos de crime e com os diferentes níveis da abordagem técnica dos casos (Pereda e col., 2009b).

As agressões sexuais são, habitualmente, mencionadas na literatura científica como "abuso sexual", sendo genericamente definidas pela OMS como o envolvimento da criança em atividades sexuais que ela não consegue compreender, que não tem capacidade e não está preparada, do ponto de vista desenvolvimental, para dar consentimento informado, e que são praticadas por um adulto ou outra criança que, por razão da idade ou desenvolvimento, se encontra numa relação de responsabilidade, confiança ou poder (WHO, 2003). Este abuso pode incluir experiências sexuais com ou sem contacto físico, como carícias sexualmente explícitas, contacto entre os órgão sexuais, sexo oral (fellatio ou cunnilingus), manobras masturbatórias ou penetração (oral, vaginal ou anal) (Finkel, 2005).

No entanto, nos casos em que as vítimas são submetidas a exame médico-legal até 72 horas após o último contacto sexual, usa-se mais frequentemente, na literatura anglo-saxónica, a expressão "acute sexual assault" (Finkel, 2005) o que, pelo menos em termos médico-legais, assume bastante relevância.

Estes casos, ditos agudos, estão mais frequentemente relacionados com agressões extrafamiliares, isoladas e associadas a maior violência física, sendo mais suscetíveis, face à sua rápida revelação, de serem provados com base em lesões e/ou vestígios físicos ou biológicos que possam ser encontrados (Taveira e col., 2009; Magalhães e col., 2009; Magalhães e col., 1998). Já os abusos sexuais são mais entendidos como associados a situações que acontecem no contexto da família, que se prolongam no tempo, que recorrem a práticas fisicamente pouco intrusivas e que só muito tardiamente são revelados (Taveira e col., 2009; Magalhães e col., 2009; Magalhães e col., 1998). No entanto, uns casos e outros podem acontecer em qualquer contexto, sendo que em Portugal o termo "abuso sexual", usado na epígrafe de um dos crimes constantes do capítulo relativo aos crimes contra a autodeterminação sexual do Código Penal (artigo $171^{\circ}$ ), não relaciona esta prática com as características que acabamos de identificar como mais frequentes nas situações de abuso, pelo que, também por este motivo, é frequente o uso generalizado do termo "abuso sexual".

Estes problemas de linguagem e concetuais dificultam a comunicação entre os diferentes atores que intervêm nestes processos e dificultam, ou até 
impedem, a comparação entre os diversos estudos que neste âmbito se realizam (Ribeiro \& Magalhães, 2010). Importa, por isso, usar uma linguagem o mais neutra possível (e.g., alegada agressão sexual) mas, sobretudo, definir sempre, e à partida, qual o significado do conceito que se está a usar, evitando-se assim confusões e interpretações incorretas quanto ao que se pretende transmitir.

\subsection{A alegada agressão sexual vs crime sexual}

De alguma forma, relacionada com o primeiro problema acima elencado, surge a questão o "uso fácil" e generalizado do conceito de "crime" quando nos referimos a agressões sexuais em geral.

Por um lado, muitas agressões sexuais configuram, em Portugal, um crime de natureza semipública, pelo que nem todos os casos, mesmo que revelados pelas vítimas, se por esta ou pelo seu representante legal não forem denunciados, irão passar nas teias da lei e, portanto, nem todos virão a constituir-se como crime.

Por outro lado, também nem todas as alegadas práticas de agressão sexual irão ser consideradas crime pelo competente tribunal, em virtude de diversos aspetos que adiante se discutirão.

Assim, e relativamente à investigação científica destes casos, impõe-se ponderar sobre o seguinte: deveremos incluir nos estudos todos os casos alegados (revelados e/ou denunciados) ou, antes, só os que mereceram condenação? A decisão dependerá, obviamente, do tipo de estudo que se pretender realizar, apenas importando, à partida, que se esclareça qual o tipo de amostra selecionada e o significado dessa amostra, dado que, como se verá, umas e outras colocam limitações na interpretação dos resultados obtidos. De qualquer forma, o ideal mesmo, será cruzar os estudos e analisar as diferenças que, relativamente a estes casos, são encontradas entre eles, sendo que ambos são fundamentais.

\subsubsection{Estudos sobre alegadas agressões sexuais}

Relativamente aos alegados casos de agressões sexuais, não deverá ser descurada a hipótese de que alguns deles possam corresponder a falsas alegações por parte das vítimas, dos seus representantes legais ou de outras pessoas que os sinalizam ou denunciam.

Estas falsas alegações podem acontecer de forma deliberada, por parte da vítima ou de terceiros, para justificar uma qualquer circunstância (e.g., adolescente que alega ter sido "violada" para justificar uma saída não autorizada pelos cuidadores), ou por má fé, tendo em vista incriminar outra pessoa 
(e.g., acusação, por um progenitor, de abuso sexual da criança, pelo outro progenitor, em caso de divórcio litigioso). Mas podem acontecer, também, por incorreta interpretação de certos factos por parte de quem levanta a suspeita (e.g., considerar um sintoma, como o prurido vulvar, como indicador altamente sugestivo ou diagnóstico de abuso sexual). Será ainda de salientar que, mesmo numa fase avançada do processo de investigação, a própria vítima, sendo criança, pode ser induzida a apresentar falsas alegações, designadamente se a sua abordagem quanto à suspeita de abuso, pelo profissional que a faz, for desadequada (Hershkowitz, 2001; Heger e col., 2002; Adams, 2008).

Assim, nem todos os casos que se apresentam como "crime" sexual, e que são encaminhados para os profissionais responsáveis pelo seu diagnóstico (no caso português, os peritos médico-legais) corresponderão, necessariamente, a uma agressão sexual. Como fazer, pois, este diagnóstico diferencial para selecionar os verdadeiros casos? A medicina legal e forense, tal como a medicina em geral, não constitui uma ciência exata; num grande número de casos, o perito médico-legal não pode limitar-se a responder sim ou não. No caso das agressões sexuais, isto é particularmente verdade, podendo-se sistematizar as dificuldades desse diagnóstico diferencial em quatro aspetos:

a) Muitos dos casos cursam com ausência de lesões e de vestígios físicos ou biológicos (Taveira e col., 2009; Magalhães e col., 2009; Magalhães e col., 1998; Heger e col., 2002; Adams, 2008; Adams e col., 1994; De Jong, Rose, 1991; Muram e col., 1991), o que não significa que a agressão não tenha acontecido. A verdade é que, em muitos deles, a inexistência destes indicadores já é esperada, tendo em conta que certo tipo de práticas abusivas não são compatíveis com a produção de lesões físicas, com a presença de material biológico do abusador ou com a transmissão de determinadas infeções (Finkel, 2005; De Jong, 1998); mas esta ausência de evidências também pode acontecer mesmo no caso de ter havido contacto físico, designadamente se sexualmente intrusivo (penetração oral, vaginal ou anal), tendo em conta que (Finkelhor, 1994; Taveira e col., 2009; Magalhães e col., 2009; Magalhães e col., 1998; Heger e col., 2002; Adams, 2008; De Jong, 1998; Becker, 1994; Pillai, 2008): (i) o uso de lubrificantes, diminuindo a fricção entre os tecidos, reduz a probabilidade de ocorrerem lesões físicas visíveis; (ii) o uso de preservativos, além da diminuição da fricção entre os tecidos, impede também o contacto entre os mesmos, impossibilitando ou dificultando a deteção de material biológico do agressor no corpo da vítima; (iii) poderá ocorrer destruição deliberada ou natural de vestígios biológicos, através da lavagem do corpo da vítima ou dos próprios atos fisiológicos da mesma (e.g., micção, defecação); (iv) na maioria dos casos não há recurso a violência, pois as vítimas não opõem resistência à agressão por medo, por não terem capacidade para entender determinadas práticas como abusivas ou, ainda, por se encontrarem sob o efeito de 
tóxicos (álcool, medicamentos, drogas de abuso ou substâncias estupefacientes); (v) geralmente a revelação da agressão sexual é tardia, sendo o exame médico-legal realizado muito tempo após o último contacto sexual, o que leva a que a maioria das lesões já tenha cicatrizado, muitas vezes sem sequelas, e que os vestígios biológicos tenham sido totalmente destruídos;

b) Nos casos em que resultam lesões ou vestígios, poucos são os indicadores atualmente considerados de diagnóstico. De facto, a não ser a gravidez e presença de sémen no corpo da vítima, todos os restantes indicadores de abuso sexual são entendidos apenas como sugestivos ou até inespecíficos (Adams, 2008; Pillai, 2008). Assim, podem existir diferentes graus de suspeição conforme as características das lesões ou vestígios encontrados (Jardim, Magalhães, 2010) mas em poucos casos se afirma categoricamente a existência de agressão sexual;

c) Podem existir lesões autoinfligidas ou provocadas por terceiros para simular a agressão sexual. Esta será, contudo, a dificuldade menos difícil de ultrapassar dado que estas lesões, sobretudo as provocadas pelo próprio, apresentam habitualmente um padrão lesional típico, caracterizando-se pela sua superficialidade e agrupamento em áreas corporais anteriores, pouco sensíveis e de fácil acesso à mão dominante, assim como pela inexistência de lesões de defesa (Faller-Marquardt e col., 1995);

d) A prova baseada no testemunho da vítima (muitas vezes a única) é geralmente pouco valorizada, sobretudo quando esse testemunho não é colhido com todas as garantias necessárias à validade desse tipo de prova, ou seja, de acordo com as normas da entrevista forense (Peixoto e col., 2011), pelo que também este valioso contributo para o diagnóstico fiável dos casos pode ficar prejudicado.

Desta forma, os estudos baseados em populações selecionadas a partir de casos alegados deverão ter sempre em conta todas estas limitações, considerando-se os casos apenas como suspeitos e admitindo-se que a amostragem possa estar construída por excesso.

\subsubsection{Estudos sobre agressões sexuais que mereceram condenação}

Relativamente aos casos judiciais, todos temos consciência de que muitas das situações arquivadas ou absolvidas poderão corresponder a efetivos crimes de natureza sexual, verificando-se tal desfecho apenas por falta de prova suficientemente robusta ou consistente - prova que, nestes casos, é particularmente difícil de produzir - ou por inimputabilidade do agressor. Tal não significa, pois, necessariamente, que a agressão não tenha ocorrido. 
Múltiplos estudos baseados em decisões judiciais relativas a alegados casos de crime sexual, revelaram que a decisão de arquivamento ou de acusação do processo por parte do Ministério Público depende de múltiplos fatores, os quais incluem o valor da prova, a idade da vítima, a probabilidade de condenação, a gravidade do crime, a relação entre o agressor e a vítima, a forma como o caso foi revelado e investigado, o grau de apoio familiar e o nível de psicopatologia da vítima (De Jong, 1998; Myers, 1993, Martone e col., 1996; Tjaden \& Thoennes, 1992; Myers, 1994). Os dois motivos mais frequentemente associados à decisão de arquivamento dos processos, de acordo com a literatura, são a falta de prova em geral e a baixa idade das vítimas (Patterson \& Campbell, 2009; Bradshaw \& Marks, 1990; Spears e col, 1997; Cross e col., 2003).

Os estudos têm revelado a existência de grandes variações quanto às taxas de acusação e de condenação no caso de crimes sexuais em geral (Ingemann-Hansen e col., 2008; Wiley e col., 2003; McGregor e col., 1999; Spears e col, 1997); no entanto, no caso dos estudos dedicados apenas aos crimes contra crianças, estas taxas têm sido semelhantes entre si (60\% e 93-94\%, respetivamente) (Patterson \& Campbell, 2009; Cross e col., 1995; Goodman e col., 1992). Tais taxas parecem estar fortemente associadas à confissão do acusado, à revelação precoce por parte da vítima e à presença de testemunhas oculares do contacto sexual (De Jong, 1998).

Resulta daqui que os estudos baseados em amostragens limitadas apenas aos casos que mereceram condenação (admitindo que todas eles estão corretamente condenados) deverão ter sempre em conta a circunstância de se estar a estudar uma população construída por defeito.

\subsubsection{Estudo do impacto dos exames médico-legais na decisão judicial}

Tendo em conta o atrás exposto, o estudo dos crimes de natureza sexual deverá incluir tanto os casos alegados como os casos condenados e, se possível, o cruzamento desses dados, tendo em conta a particular complexidade destas situações, principalmente no que se refere à sua deteção, bem como ao diagnóstico médico-legal e forense.

Esta análise conjunta poderá permitir aprofundar o conhecimento e a compreensão quanto a esta realidade, o que é fundamental para promover a melhoria de práticas em todos os níveis da intervenção, designadamente no que ao diagnóstico médico-legal e forense diz respeito. De facto, é necessário garantir a validade desse diagnóstico dado que um diagnóstico errado poderá permitir perpetuar uma situação de agressão sexual ou contribuir para punir um inocente e/ou separar uma família (Jardim, Magalhães, 2010). 
Neste sentido, a boa administração da justiça passa, também, pela segurança da prova médico-legal e forense, pelo que se torna importante, nesta fase do estado da arte, conhecer o efeito da avaliação médico-legal nas decisões judiciais. Sobre esta matéria, a literatura estrangeira refere que esta avaliação parece ter alguma influência na acusação e condenação, apesar de esta relação ainda não ter sido bem estudada e determinada (De Jong, 1998; Patterson \& Campbell, 2009). Em Portugal, apenas se encontrou um estudo publicado em revista indexada, relativo a casos que tiveram lugar entre 1992 e 1995, incluindo, contudo, vítimas de todas as idades e apresentando uma amostra muito reduzida, o que limita as suas conclusões (Pinto da Costa e col., 1998); de qualquer forma, as conclusões nele apresentadas são semelhantes às atrás referidas.

\subsection{Objetivos do estudo}

Do exposto, conclui-se que no estudo das agressões sexuais de crianças, é fundamental o conhecimento das decisões judiciais e o efeito da avaliação médico-legal nas mesmas. Este tipo de análise já está disponível na literatura em relação a alguns países, tal como referido, o mesmo não se tendo ainda verificado em Portugal.

Assim, o objetivo geral deste estudo é contribuir para melhor caracterizar, na perspetiva médico-legal e forense, e em Portugal, as agressões sexuais contra crianças, tendo em vista promover a capacidade dos profissionais para as detetar e diagnosticar precocemente.

Os objetivos específicos são: (a) Caracterizar e comparar os casos de agressão de natureza sexual que foram objeto de condenação e os que foram arquivados ou absolvidos; (b) Determinar o valor da avaliação médico-legal e forense na tomada de decisão judicial, identificando os pontos fortes e fracos da mesma, para que, desta forma, se possam delinear estratégias de intervenção adequadas à nossa realidade.

\section{MATERIAL E MÉTODOS}

Foi realizado um estudo retrospetivo baseado na análise de relatórios periciais selecionados de acordo com os seguintes critérios de inclusão: (a) Alegados crimes de natureza sexual (independentemente do contexto intra ou extrafamiliar e da data da sua ocorrência); (b) Vítimas com idade inferior a 18 anos; (c) Submetidas a exame médico-legal nos serviços do norte do Instituto Nacional de Medicina Legal, I.P. (delegação do norte e gabinetes médico-legais 
de Braga, Bragança, Chaves, Guimarães, Mirandela, Penafiel, Santa Maria da Feira, Viana do Castelo e Vila Real); (d) Entre 2004 e 2008; (e) Para os quais se obteve os despachos de arquivamento proferidos em sede de inquérito e as sentenças judiciais provenientes, respetivamente, dos serviços do Ministério Público e dos Tribunais Criminais de circunscrições judiciais incluídas na área de competência territorial correspondentes à Delegação do Norte do Instituto Nacional de Medicina Legal, I.P. (INML). Considerou-se como limite o ano de 2008, por se admitir como estimativa razoável para o tempo médio de resolução dos casos a nível do Tribunal Criminal, o período de 2 anos.

Tendo em conta os critérios de inclusão atrás descritos, foram identificados 1047 relatórios médico-legais, relativamente aos quais foram requeridas, por correio, aos serviços do Ministério Público e Tribunais Criminais das respetivas áreas, todas as correspondentes decisões judiciais. No entanto, apenas foram disponibilizadas para o presente estudo 185 decisões, as quais correspondem a $17.7 \%$ das solicitadas.

Para a execução deste trabalho, foi utilizada uma ficha de recolha de dados construída para o efeito, a qual foi aplicada apenas pela investigadora, assegurando, desta forma, a fiabilidade na colheita dos dados. A ficha incluía 134 questões, divididas nas seguintes secções (a) Identificação do processo; (b) Caracterização da vítima; (c) Caracterização do suposto agressor; (d) Caracterização do suposto crime; (e) Observação clínica; (f) Exames complementares de diagnóstico; (g) Entrevista forense; (h) Conclusões médico-legais; (i) Conclusões judiciais.

Relativamente às expressões utilizadas nesta exposição, importará assinalar que, no que à vítima se refere, foi tida em conta a Lei 112/2009, de 16 de setembro, a qual refere que "após apresentada a denúncia da prática do crime e não existindo fortes indícios de que a mesma é infundada, é atribuído à vítima, para todos os efeitos legais, o estatuto de vítima" e não de "alegada vítima". Já quanto ao suspeito e ao ato cometido pelo mesmo, usaram-se as expressões "alegado agressor" e "alegada agressão", tendo em conta o artigo $32^{\circ}$ da Constituição Portuguesa, o qual refere que "o arguido presume-se inocente até ao trânsito em julgado da sentença de condenação".

Na colheita dos dados relativos ao tipo de práticas e às lesões observadas, quando estes eram múltiplos, foi considerada apenas a prática fisicamente mais intrusiva e a lesão de natureza sexual mais grave. A classificação das lesões em "sugestivas" e "inespecíficas" foi efetuada de acordo com as "Guidelines for Medical Care of Children Who May Have Been Sexually Abused" (Adams, 2008).

As conclusões médico-legais dos relatórios periciais apresentavam-se formuladas de acordo com a seguinte classificação: (a) "Demonstrável"; (b) "Provável"; (c) "Possível mas não demonstrável"; (d) "Duvidoso"; (e) "Incompatível". No entanto, a classificação mais frequentemente referida na 
literatura internacional (Adams, 2008) é: (a) "Diagnóstico"; (b) "Sugestivo"; (c) "Inespecífico"; esta última classificação revela-se, também, mais útil para efeitos de análise estatística. Assim, estabeleceu-se a seguinte correspondência: (a) "Demonstrável” - "Diagnóstico"; (b) "Provável” - "Sugestivo"; (c) "Possível mas não demonstrável", "Duvidoso" e "Incompatível” - "Inespecífico".

Foi efetuado um estudo estatístico comparativo entre os casos em que o arguido foi condenado (CC) e os casos em que não houve condenação (CNC) - processo arquivado, suspenso provisoriamente ou arguido absolvido. Para a base de dados recorreu-se ao programa informático Excel 2010. A análise estatística foi efetuada no PASW Statistics 18.0 (IBM SPSS software) para Windows. O teste Qui-quadrado de Pearson e o teste de Fisher foram utilizados nas comparações e verificação de independência de variáveis categóricas. Para a análise das variáveis quantitativas, realizou-se o teste $t$-student. Admitiu-se um nível de significância de 0.05 , não se tendo considerado para efeito desta análise os casos em que não havia informação disponível.

\section{RESULTADOS}

\subsection{Caracterização das decisões judiciais}

A análise das 185 decisões judiciais revelou que a maioria dos casos (68.1\%) foram arquivados pelo Ministério Público e apenas 30.8\% foram acusados e julgados; em 2 deles (1.1\%), o processo foi provisoriamente suspenso (SPP) (Figura 1). O motivo mais frequente para o arquivamento foi a insuficiência ou ausência de provas $(54.8 \%$ ) (Figura 1). Nas acusações, o crime mais frequentemente considerado foi o "abuso sexual de crianças" - artigo $171^{\circ}$ do Código Penal (73.7\%).

Dos casos acusados ( $n=57), 14 \%$ foram absolvidos e $86 \%$ condenados, correspondendo isto, respetivamente, a $4.3 \%$ e $26.5 \%$ do total dos casos iniciais (Figura 1).

Aos condenados, foi aplicada pena de prisão em $49 \%$ dos casos e pena suspensa em $42.8 \%$ (Figura 1). Quatro condenados (8.2\%) foram considerados inimputáveis em razão da idade ou por patologia do foro psiquiátrico, tendo-lhes sido aplicadas apenas medidas de segurança (internamento em centros de reabilitação). Em média, a pena foi de 49.4 meses (min.=6; máx.=144; $\mathrm{SD}=33.8$ ). Em 7 casos, o condenado recorreu da sentença para os Tribunais da Relação e para o Supremo Tribunal de Justiça, mas a medida da pena não foi alterada, com exceção de 3 casos em que passou de efetiva para suspensa. 
O tempo médio decorrido entre o exame médico-legal e a decisão judicial final foi de 14 meses (min.=1; máx.=45; $\mathrm{SD}=11.3$ ), sendo nos casos arquivados ou provisoriamente suspensos de 10.6 meses e nos julgados de 22.4 meses.

A partir destes casos foram criados dois grupos, os quais serão alvo de análise comparativa nos resultados que se seguem: os casos que não foram condenados (CNC) e os casos condenados (CC) (73.5\% e 26.5\%, respetivamente).

\subsection{Caracterização da vítima}

As vítimas eram maioritariamente do género feminino $(78.4 \%)$, com idade média de 9.8 anos (min.=0.35; max.=16.64; SD=4.03) - 10.5 anos nos $\mathrm{CC}$ e 9.6 anos nos CNC, não sendo esta diferença estatisticamente significativa ( $\mathrm{r}=0.33$ ) (Tabela 1). Quanto ao tipo de atividade, $72.3 \%$ dos casos em que havia informação eram estudantes. Dos restantes, $\mathrm{n}=45$ ainda não atingido a idade escolar e 4 eram portadores de handicap mental, pelo que não exerciam qualquer atividade. Comparando os grupos relativos aos $\mathrm{CC} \mathrm{e}$ $\mathrm{CNC}$, encontrou-se uma associação significativa entre os mesmos, ocorrendo a condenação sobretudo nos casos que envolvem crianças em idade escolar $(\mathrm{r}<0.05)$ (Tabela 1). Relativamente ao tipo de família, não se encontraram diferenças significativas entre os dois grupos em estudo $(r=0.33)$, sendo que a maior parte integra uma família nuclear $(47 \%$ dos casos em que existe informação) - Tabela 1.

\subsection{Caracterização do alegado agressor}

Os alegados agressores eram maioritariamente do género masculino (99.5\%) (Tabela 2). Apenas num dos casos o suposto crime terá sido perpetrado por uma mulher (ama) que, segundo a informação, terá "acariciado" a região genital de criança com 2 anos de idade; no entanto, este caso foi arquivado por falta de provas. A análise dos grupos etários e da atividade ocupacional dos alegados agressores (nos casos em que havia informação disponível), indica que estes se encontravam, na sua grande maioria, em idade ativa e exercendo uma atividade profissional (Tabela 2). Verificou-se, no entanto, que em $19.3 \%$ dos casos conhecidos se tratavam de indivíduos menores de idade, sendo a idade mínima de 13 anos. A idade máxima conhecida do suposto agressor foi de 74 anos. Em 85.4\% dos casos, o alegado agressor era alguém conhecido da vítima (50.3\% familiares e 35\% conhecidos). Não se encontraram diferenças significativas entre os dois grupos em estudo quanto a este aspeto ( $r=0.13$ ): (a) familiares, em $53 \%$ dos CC e 49\% dos CNC; (b) conhecidos, em 40.8\% dos CC e 33\% dos CNC; (c) desconhecidos, em 6\% dos CC e $17.6 \%$ dos CNC (Tabela 2). 


\subsection{Caracterização da primeira suspeita}

A primeira suspeita quanto à possível ocorrência de crime de natureza sexual partiu, mais frequentemente, de familiares (56.2\% dos casos em que existe informação), os quais fizeram a sinalização e/ou denúncia. Não se verificaram diferenças significativas na comparação entre os dois grupos em estudo ( $\mathrm{r}=0.57)$; essa suspeita foi levantada por familiares $(30.6 \%$ dos CC e $32.4 \%$ dos $\mathrm{CNC}$ ) e por não familiares (28.6\% dos CC e $23.5 \%$ dos $\mathrm{CNC}$ ) de forma idêntica (Tabela 3).

Na maior parte dos casos a suspeita teve como fonte a revelação feita pela vítima ( $57.1 \%$ dos casos em que existe informação). Verificou-se existir diferenças significativas entre os CC e CNC $(r<0.05)$, demonstrando-se que a condenação se verifica mais quando a primeira suspeita assenta na revelação feita pela vítima ou quando existem testemunhas oculares das referidas práticas e que a não condenação se verifica mais quando a primeira suspeita é baseada apenas na observação de sinais e sintomas sugestivos de contacto sexual, tendo em conta que, para ambas as situações, os valores obtidos, para cada um dos itens, foram superiores aos esperados pelo cálculo estatístico. Assim, considerando os dois grupos, a suspeita teve por base a: (a) observação de sinais e sintomas considerados sugestivos de contacto sexual (6\% dos CC e $19.1 \%$ dos CNC); (b) revelação pela vítima (42.9\% dos CC e $31.6 \%$ dos CNC); (c) presença de testemunhas oculares (16.3\% dos CC e $8.1 \%$ dos CNC) (Tabela 3).

A suspeita foi predominantemente comunicada aos serviços de saúde (44.4\% dos casos em que existe informação), polícias e comissões de proteção de crianças e jovens em perigo (CPCJ) (Tabela 3). Não se verificou existir diferenças estatísticas significativas entre os dois grupos em estudo $(\mathrm{r}=0.95)$.

\subsection{Caracterização da alegada agressão}

O tipo de práticas maioritariamente descritas foram as carícias sexualmente explícitas (33.5\%): 38.8\% dos CC e 31.6\% dos CNC. A penetração vaginal e/ou anal foi referida em $27 \%$ dos casos: $34.7 \%$ dos CC e $24.3 \%$ dos CNC (Tabela 4). Não foram observadas diferenças estatisticamente significativas entre os dois grupos em estudo ( $\mathrm{r}=0.66)$ (Tabela 4).

Na grande maioria dos casos em que existe informação, o alegado crime terá ocorrido na casa da vítima e/ou agressor (65.1\%) - Tabela 4; não foram identificadas diferenças estatísticas significativas entre os dois grupos quanto ao local dos supostos factos $(\mathrm{r}=0.16)$.

Em relação à frequência das práticas sexuais, estas terão sido recorrentes em $43.6 \%$ dos casos em que existe informação. Verificaram-se diferenças 
significativas entre os dois grupos em estudo $(r<0.05)$, demonstrando-se que a condenação se verifica mais quando as práticas abusivas são reiteradas.

As ameaças verbais e a violência física aconteceram em $30.4 \%$ e $32.9 \%$ dos casos em que existe informação, respetivamente (Tabela 4); não se encontraram diferenças significativas entre os dois grupos em análise $(r=0.14)$.

\subsection{Caracterização da perícia médico-legal e forense}

O intervalo de tempo entre o último contacto sexual e o exame médico-legal foi superior a 72 horas na maior parte dos casos (75.7\%), verificando-se em $77.6 \%$ e 75\%, respetivamente para os CC e os CNC (Tabela 5). Não se detetaram diferenças estatisticamente significativas na comparação entre estes dois grupos $(\mathrm{r}=0.72)$.

$\mathrm{Na}$ grande maioria dos casos não foram diagnosticadas quaisquer lesões ou sequelas (68.1\%): 69.4\% e 67.6\%, respetivamente para os CC e os CNC (Tabela 5). As lesões sugestivas de contacto sexual apenas foram detetadas em $16.3 \%$ dos CC e em $11.8 \%$ dos CNC, não havendo associação estatística entre os grupos ( $\mathrm{r}=0.51$ ) (Tabela 5). Num dos CC, a vítima, de 16 anos, engravidou do agressor (pai), tendo voluntariamente interrompido a gravidez.

Os estudos de genética e biologia forense para análises de ADN tiveram lugar em $18.4 \%$ dos casos (20.4\% dos CC vs $17.7 \%$ dos CNC). Destes, em apenas $10.2 \%$ dos $\mathrm{CC}$ e em $1.5 \%$ dos $\mathrm{CNC}$, se obteve um perfil genético diferente do da vítima nas amostras biológicas recolhidas do seu corpo ou roupas ou, ainda, no exame do local (Tabela 5). Estes resultados revelaram significância estatística entre os dois grupos em estudo $(r<0.05)$, demonstrando-se que a condenação se verifica mais quando é detetado um perfil genético heterólogo na vítima. Os casos em que se obteve um perfil genético heterólogo e que não foram condenados $(\mathrm{n}=2)$ corresponderam a: (a) adolescente do género feminino, com 15 anos, que terá mantido "relações sexuais consentidas" com o namorado de 22 anos, tendo o processo sido arquivado por "prova insuficiente"; (b) adolescente do género feminino, com 13 anos, que seria alegadamente abusada pelo pai desde os 6 anos, tendo o alegado agressor sido absolvido por "prova insuficiente"; o perfil genético do suposto agressor foi obtido de um cobertor, que terá sido apontado pela examinada como local para onde o seu pai terá ejaculado após a agressão, não tendo os resultados deste exame genético sido mencionados a nível da decisão judicial.

Os estudos toxicológicos e microbiológicos foram conduzidos apenas em $13 \%$ e $2.7 \%$ de todos os casos, respetivamente. Não foram obtidos quaisquer resultados positivos em nenhuma das situações, pelo que não se efetuaram estudos de correlação (Tabela 5). 
A entrevista forense só foi efetuada em 52.4\% de todos os casos $(57.1 \%$ dos CC vs 50.7\% dos CNC) (Tabela 5), decorrendo sempre posteriormente ao exame médico-legal. Não se encontraram associações significativas entre os dois grupos $(\mathrm{r}=0.44)$.

Com base na análise de toda a informação disponível (que podia incluir resultados do exame físico, dos exames laboratoriais e da entrevista forense), as conclusões da perícia médico-legal foram maioritariamente no sentido de se considerarem os achados inespecíficos para o diagnóstico de agressão sexual (89.2\%). Apenas em 7\% dos casos os achados foram considerados como sugestivos e em 3.8\% como diagnósticos. Relativamente aos grupos em estudo, os resultados foram os seguintes: (a) diagnóstico (8.2\% dos CC e $2.2 \%$ dos CNC); (b) sugestivo (16.3\% dos CC e 3.7\% dos CNC); (c) inespecífico (75.5\% dos CC e 94.1\% dos CNC) (Tabela 6). Estes resultados apresentam diferenças estatisticamente significativas, demonstrando que a condenação se verifica mais quando o exame médico-legal diagnostica o contacto sexual ou é sugestivo de tal $(\mathrm{r}<0.05)$.

\section{DISCUSSÃO}

Em Portugal existem já alguns estudos publicados em revistas indexadas sobre crimes de natureza sexual perpetradas contra crianças, relativamente aos aspetos médico-legais e forenses (Taveira e col., 2009; Magalhães e col., 2009; Magalhães e col., 1998), mas todos eles baseados em alegados casos. Este será o primeiro que analisa, também, os casos que foram alvo de decisão judicial, avaliando o efeito do exame médico-legal nessas decisões.

\subsection{0 alegado abuso sexual. Casos não condenados vs casos condenados}

A análise dos alegados casos de crimes de natureza sexual revelou que a maioria das vítimas é do género feminino (78.4\%), com idade média de 9.8 anos, estudante $(69.2 \%)$, tendo sido supostamente abusadas por um indivíduo do género masculino (99.5\%), seu conhecido (85.4\%) e que pertencia à sua família em $50.3 \%$ dos casos. Na maioria, a revelação foi feita pela vítima (57.1\%) a um elemento da família (56.2\% dos casos em que existe informação), o qual comunicou a situação maioritariamente aos serviços de saúde $(44.4 \%$ dos casos em que existe informação). A alegada agressão terá ocorrido, predominantemente, em casa da vítima e/ou do suposto agressor (65.1\% dos casos em que existe informação), sob ameaças verbais e/ou violência física (30.4\% e $32.9 \%$, respetivamente, dos casos em que existia informação), com recurso a práticas sexuais reiteradas (43.6\% dos casos em que existia informação). 
Estas foram, mais frequentemente, carícias sexualmente explícitas $(33.5 \%)$ e penetração vaginal e/ou anal (27\%). Em 75.7\% dos casos, o intervalo de tempo entre o último contacto sexual e o exame médico-legal foi superior a 72 horas e na grande maioria dos casos $(68.1 \%)$ não foram diagnosticadas quaisquer lesões, sendo que as sugestivas de contacto sexual apenas terão sido diagnosticadas em $13 \%$ das vítimas. Os estudos de ADN foram realizados em apenas $18.4 \%$ dos casos e, destes, apenas $20.6 \%$ detetaram um perfil genético diferente do da vítima nas amostras biológicas recolhidas do seu corpo, roupas e/ou no exame do local. Os exames toxicológicos e microbiológicos foram realizados em muito poucas situações (13\% e $2.7 \%$, respetivamente) e a entrevista forense foi efetuada em cerca de metade dos casos (52.4\%). O exame médico-legal considerou os achados diagnósticos e sugestivos em apenas 3.8\% e 7\% de todos os casos, respetivamente. Note-se que, apesar de terem sido identificadas lesões sugestivas em 13\% dos casos, não se verificou uma correspondente conclusão médico-legal (apenas em 7\% os achados foram considerados sugestivos), dado que esta conclusão considera não apenas o valor diagnóstico da lesão mas esse valor analisado no contexto de toda a situação.

Estes resultados estão, na maioria dos aspetos, de acordo com a bibliografia nacional e estrangeira já publicada sobre o tema para este tipo de amostras (Taveira e col., 2009; Magalhães e col., 2009; Magalhães e col., 1998; De Jong e col., 1983; Csorba e col., 2005; Fischer \& Macdonald, 1998), tendo-se contudo verificado alguma discrepância no que se refere à percentagem de abusos intrafamiliares. No presente estudo, este valor é de cerca de $50 \%$, sendo superior ao apresentado pelos estudos anteriormente citados (25-40\%). Estas diferenças podem resultar da utilização de diferentes amostras no que se refere à sua dimensão ou época do estudo, por exemplo, mas também podem dever-se a um aumento da denúncia dos casos de abuso intrafamiliar em Portugal, resultado da melhor intervenção dos profissionais no terreno, cada vez mais sensibilizados e atentos a esta problemática, às suas especificidades e à sua particular gravidade (Magalhães e col., 2009; Fischer \& Macdonald, 1998).

\subsection{Decisões judiciais}

A análise das decisões judiciais revelou que:

a) $68.1 \%$ dos casos foram arquivados ao nível do Ministério Público, a maioria por falta de provas $(54.8 \%)$, tendo $30.8 \%$ dos casos sido acusados. A literatura publicada está de acordo quanto ao facto da maior parte dos casos serem arquivados por falta de provas (De Jong, 1998; Becker, 1994; Pillai, 2008; Jardim \& Magalhães, 2010; Faller-Marquardt e col., 1995; Myers, 1993, Martone e col., 1996; 
Tjaden \& Thoennes, 1992; Myers, 1994; Patterson \& Campbell, 2009; Bradshaw \& Marks, 1990; Spears \& Spohn, 1996). Mas observam-se grandes variações no que se refere às taxas de acusação, principalmente nos trabalhos mais recentes, onde estas variam entre os 28\% e os 94\% (Bradshaw \& Marks, 1990; Cross e col., 2003; Ingemann-Hansen e col., 2008; Wiley e col., 2003; McGregor e col., 1999; Spears e col, 1997). Estas variações podem ser explicadas por diferenças de amostragem e das metodologias de estudo, as quais podem estar influenciadas por questões culturais, sociais e legais (Pereda e col., 2009b; WHO, 2003), que variam entre diferentes países e, por vezes, dentro do mesmo país (WHO, 2003).

b) $1 \%$ dos processos foram suspensos provisoriamente (SPP), de acordo com o artigo $281^{\circ}$ do Código de Processo Penal português. Este artigo prevê que no caso de um suspeito que nunca tenha sido condenado por um crime de natureza sexual, nem beneficiado anteriormente de SPP, e que cumpra todas as regras de conduta que lhe forem impostas, o Ministério Público, com a concordância do Juiz de Instrução e do próprio suspeito, pode suspender o processo de forma provisória, até ao máximo de cinco anos, e arquivá-lo posteriormente;

c) Os alegados agressores foram condenados em $86 \%$ dos casos acusados $(26.5 \%$ do total dos casos). Estes resultados estão também de acordo com a literatura, que revela que a probabilidade de condenação é muito grande nos casos que são acusados e julgados (93-94\%) (Patterson \& Campbell, 2009; Bradshaw \& Marks, 1990; Cross e col., 1995; Goodman e col., 1992);

d) Nos casos condenados, houve pena de prisão efetiva ou suspensa em $49 \%$ e $42.8 \%$, respetivamente. O tempo médio das penas foi de 4.1 anos, o que é inferior aos resultados de cerca de 7 anos encontrados em estudos estrangeiros (Martone e col., 1996; Sugue-Castillo, 2009). Este valor está diretamente relacionado com a lei penal de cada país;

e) O tempo médio decorrido entre o exame médico-legal e a decisão judicial final foi de 22.4 e 10.6 meses para os casos julgados e para os arquivados/provisoriamente suspensos, respetivamente. Note-se, contudo, que este valor médio poderá ainda ser maior para os casos sujeitos a julgamento, pois só se obtiveram 17.7\% de todos os casos solicitados, sendo que muitos deles poderão não ter sido disponibilizados por ainda não estarem concluídos. Estes resultados justificam a opção de neste estudo só terem sido incluídos casos sujeitos a exame médico-legal até ao fim de 2008, pretendendo-se, com isto, reduzir o mais possível a taxa de casos ainda não concluídos. 


\subsection{Aspetos com impacto na decisão judicial}

O estudo revelou diferenças estatisticamente significativas entre os casos condenados e os não condenados $(\rho<0.05)$, estando as condenações predominantemente associadas à: (a) Idade da vítima; (b) Revelação do abuso; (c) Frequência do abuso; (d) Estudos de DNA; (e) Conclusões médico-legais.

\subsubsection{Idade da vítima}

Relativamente à idade das vítimas, não se encontraram diferenças estatisticamente significativas entre os casos condenados e os não condenados $(\rho=0.12)$, apesar da média de idades das vítimas dos CC ser ligeiramente superior aos CNC (10.5 vs 9.6 anos). No entanto, o presente estudo revelou que os casos com vítimas em idade escolar apresentavam maior taxa de condenação do que as que, por razão da idade ou handicap mental, não tinham iniciado esta atividade $(\rho<0.05)$. Ora, este aspeto não pode ser dissociado da idade, verificando-se, portanto, uma relação das condenações com a mesma. Também vai neste sentido a literatura publicada, a qual refere que a baixa idade é uma das razões mais associadas ao arquivamento processual (Patterson \& Campbell, 2009; Bradshaw \& Marks, 1990; Spears \& Spohn, 1996). Isto poderá estar associado com a maior dificuldade das crianças mais pequenas para revelarem e/ou testemunharem o abuso, bem como com o tipo de práticas (fisicamente menos intrusivas) a que nestes casos os mais pequenos são geralmente sujeitos (Magalhães e col., 2009).

\subsubsection{Revelação do abuso}

Os casos em que a primeira suspeita da existência de um crime de natureza sexual assentou na revelação feita pela própria vítima ou na presença de uma testemunha ocular quanto às práticas abusivas, associaram-se a uma probabilidade aumentada de condenação. Por outro lado, os casos em que esta suspeita se baseou na observação de sinais e sintomas identificados, na maioria das vezes, por familiares ou conhecidos, sem formação especializada na área médica ou médico-legal, estiveram significativamente correlacionadas com a não condenação. Estes resultados são corroborados com os estudos publicados, que associam a revelação das práticas abusivas por parte da vítima e a presença de testemunhas oculares a maiores taxas de condenação (De Jong, 1998).

No entanto, a presença de testemunhas oculares é rara neste tipo de situações, pois, como se demonstrou, uma grande percentagem dos casos são intrafamiliares $(50.3 \%)$ e ocorrem dentro das casas das próprias vítimas e/ou agressores (65.1\%), o que está de acordo com outros estudos (Taveira e col., 
2009; Magalhães e col., 2009; Magalhães e col., 1998; De Jong e col., 1983; Csorba e col., 2005; Fischer \& Macdonald, 1998), levando a que o testemunho da criança seja uma das provas mais importantes (Peixoto e col., 2011). Dada essa importância, é essencial criar estratégias para a otimização do processo de entrevista forense, não só com o objetivo de preservar o relato, sem o contaminar mas, também, para a prevenção da vitimização secundária da criança (Peixoto e col., 2011; Peixoto, Ribeiro, 2010; Magalhães, Ribeiro, 2007; Ribeiro, 2009). No entanto, e apesar das diversas alterações da lei penal portuguesa nas últimas décadas, as crianças vítimas destes tipos de crime, continuam a ser interrogadas múltiplas vezes, como demonstra um estudo português, publicado em 2009 (Ribeiro, 2009), referindo que estas vítimas têm que prestar, em média, 8 depoimentos durante o decorrer de todo o processo. A investigação sobre o desenvolvimento humano mostra que as crianças apresentam características específicas de linguagem, memória e sugestionabilidade, que só um profissional especializado pode controlar durante a entrevista (Peixoto e col., 2011). Neste sentido, as mais recentes guidelines médico-legais portuguesas sobre a intervenção forense nos casos de abuso sexual de crianças (Magalhães e col., 2011), referem que deverá ser efetuada entrevista forense a todas as crianças alegadamente vítimas de crimes de natureza sexual, sendo que os restantes profissionais que intervêm no processo devem limitar ao estritamente necessário a abordagem da criança quanto aos factos ocorridos.

Mas, o que se verificou no presente estudo, foi que a entrevista forense foi apenas solicitadas em 52.4\% dos casos, não se verificando qualquer correlação significativa com os casos condenados. Isto pode dever-se, não só ao facto das referidas guidelines só terem sido publicadas em 2011, mas principalmente porque no período em estudo não se contava com uma equipa de entrevistadores forenses capazes de dar resposta a todas as necessidades do país; este último aspeto já se encontra solucionado desde 2011, através do INML.

\subsubsection{Frequência do abuso}

Os resultados deste estudo demonstraram que a condenação é mais provável quando as práticas abusivas são reiteradas. Este facto encontra-se fortemente associado aos abusos intrafamiliares que, pela relação de proximidade entre a vítima e o agressor, a sua baixa visibilidade e o seu grande impacto psicológico na vítima (Taveira e col., 2009; Magalhães e col., 2009; Magalhães e col., 1998), são considerados particularmente graves (Myers, 1993; Martone e col., 1996; Tjaden \& Thoennes, 1992; Myers, 1994), sendo por isso imperativo um diagnóstico precoce. No entanto, o diagnóstico nestas situações é muito difícil, tendo em conta que os casos intrafamiliares estão envoltos 
em dinâmicas particulares de segredo, ocorrem maioritariamente dentro das casas dos próprios abusadores e incluem práticas sexuais fisicamente pouco intrusivas e sem recurso a violência física, levando ao atraso do conhecimento público da situação e reduzindo a probabilidade de se observarem vestígios de contacto sexual (Taveira e col., 2009; Magalhães e col., 2009; Magalhães e col., 1998; De Jong e col., 1983; Fischer \& Macdonald, 1998). Nesse sentido, a informação da população em geral, e das crianças e adolescentes em particular, sobre esta matéria, mostra-se particularmente relevante.

\subsubsection{Perícia médico-legal e forense}

Relativamente à relação entre os procedimentos e conclusões médico-legais e as decisões judiciais, este estudo revelou a existência de diferenças estatisticamente significativas entre os casos condenados e os não condenados, estando os primeiros predominantemente associados ao achado de um perfil genético heterólogo no decurso dos exames forenses e a uma conclusão diagnóstica ou sugestiva de contacto sexual no relatório médico-legal.

\subsubsection{Presença de perfil genético heterólogo}

Um dos principais objetivos da avaliação médico-legal é a colheita de vestígios biológicas para estudos de $\mathrm{ADN}$, o que deverá acontecer nas primeiras 72 horas após o contacto sexual, para viabilizar os estudos (WHO, 2003; Finkel, 2005; Jardim \& Magalhães, 2010). Ora, dado que a maior parte dos casos são tardiamente revelados (75.7\% depois das 72 horas), apenas em $18.4 \%$ das situações estudadas foram feitas colheitas para estudos de ADN.

Os estudos genéticos, neste tipo de casos, consistem na determinação de perfis genéticos contidos nas amostras disponibilizadas, que provém maioritariamente do corpo da vítima (particularmente das mucosas oral, anal e genital) e da roupa que esta usava durante as práticas abusivas.

Segundo os resultados do presente estudo, as condenações são mais prováveis quando é encontrado um perfil genético diferente do da vítima nas amostras biológicas colhidas no seu corpo e/ou roupas (10.2\% dos casos condenados). Este resultado era, aliás, expectável, tendo em conta que na literatura (Finkel, 2005; Adams, 2008; Stewart, 2011) este tipo de vestígio é considerado como um dos poucos indicadores diagnósticos de contacto sexual.

No entanto, a maioria dos estudos publicados sobre este tema negligencia esta associação, o que pode ser explicado por diversos fatores: (a) a maioria destes exames médico-legais não é efetuada nas primeiras 72 horas após o último contacto sexual (Taveira e col., 2009; Magalhães e col., 2009; 
Magalhães e col., 1998; Fischer, Macdonald, 1998); (b) a maioria das vítimas não apresenta indicadores físicos ou biológicos de contacto sexual (Taveira e col., 2009; Magalhães e col., 2009; Magalhães e col., 1998; Heger e col., 2001; Adams, 2008; De Jong \& Rose, 1991; Muram e col., 1991; De Jong, 1998; Patterson \& Campbell, 2009; Bradshaw \& Marks, 1990); (c) nos casos pediátricos alguns autores consideram que não se devem efetuar zaragatoas para pesquisa de ADN após as $13 \mathrm{~h}$ após o último contacto sexual (Christian e col., 2000) e outros consideram que só se devem colher estas amostras em crianças com mais de 10 anos (Palusci e col., 2006); (d) em alguns países em desenvolvimento, a tecnologia necessária para estudos genéticos não se encontra disponível devido ao seu elevado custo e os resultados dos testes genéticos não são admissíveis como prova em tribunal por não haver controlo dos procedimentos e garantia da cadeia de custódia (Sugue-Castillo, 2009).

Estes aspetos realçam a importância da deteção e intervenção precoces, que poderão ser efetuadas pelos profissionais que estão em contacto direto e diário com estas vítimas (professores, educadores de infância, pediatras, clínicos gerais, ginecologistas, enfermeiros, psicólogos, polícias, assistentes sociais, entre muitos outros). No entanto, para detetar um crime desta natureza é necessário que estes profissionais estejam alertados para a possibilidade da sua ocorrência e conheçam os sinais e sintomas que lhes estão associados, sendo para tal necessária formação especializada.

\subsubsection{Conclusões médico-legais}

Este estudo demonstra que as condenações neste tipo de crimes são mais prováveis quando as conclusões médico-legais, após a conjugação de todos os elementos disponíveis (resultados do exame físico, estudos genéticos, microbiológicos e toxicológicos, bem como da entrevista forense), consideram os achados como diagnósticos ou sugestivos de contacto sexual.

Note-se, no entanto, que para tal é necessário que os peritos médicos responsáveis pela avaliação destes casos solicitem os exames laboratoriais necessários e adequados a cada situação e interpretem todos os achados como um todo, que se potenciam entre si, e não apenas como a soma das partes. Para que isso suceda, é necessário que o exame médico-legal seja efetuado por peritos médicos especializados na área da sexologia forense, fazendo sempre recurso à foto ou vídeo-documentação dos casos, cujo objetivo não é só o de melhorar a prova mas, também, permitir o peer review de cada um dos casos.

A inexperiência do perito médico nas práticas forenses de observação de lesões ou sequelas, colheita, e acondicionamento das amostras biológicas, assim como na interpretação dos achados, pode comprometer todo o pro- 
cesso judicial (Patterson \& Campbell, 2009; Bradshaw \& Marks, 1990; De Munnynck e col., 2006).

No entanto, na maioria dos países o exame médico-legal por suspeita de crime de natureza sexual não é efetuado por médicos especializados na área forense mas sim por médicos especializados na área clínica (pediatras, ginecologistas, cirurgiões, clínicos gerais), que muitas vezes se encontram nos serviços de urgência. Um estudo americano publicado em 2009 (Patterson \& Campbell, 2009) demonstra que as taxas de acusação pelo Ministério Público são significativamente maiores quando os casos são avaliados por médicos especializados na área forense, se comparados com os casos que são avaliados por médicos sem especialização nesta área. Este facto pode também contribuir para explicar porque razão os estudos publicados ainda não são claramente conclusivos quanto ao impacto do exame médico-legal e forense nas decisões judiciais (De Jong, 1998; Patterson \& Campbell, 2009).

Em Portugal, a realização de exame médico-legal em todos os casos de crimes de natureza sexual encontra-se salvaguardada pelo Código de Processo Penal, que obriga a que todas as vítimas de crimes desta natureza sejam observadas por peritos médicos pertencentes ao INML. Para isso, têm sido criados protocolos de atuação entre os serviços médico-legais, os hospitais, os Ministérios Públicos, as Comissões de Proteção de Crianças e Jovens e, mais recentemente, entre os Ministérios da Saúde e da Justiça, e a Comissão Nacional de Proteção de Crianças e Jovens em Risco, tendo em vista a correta e atempada intervenção neste tipo de situações.

\subsection{Pontos fortes e fracos da intervenção médico-legal e forense}

Os resultados deste trabalho permitem inferir que a perícia médico-legal e forense contribui de forma significativa para a decisão judicial. Mas, ainda quanto a esta perícia, importa identificar os seus pontos fortes e fracos para que, desta forma, se possam delinear estratégias de intervenção adequadas à nossa realidade.

Como pontos fortes, podemos considerar os seguintes aspetos:

a) As perícias médico-legais e forenses serem sempre efetuadas por peritos forenses do INML, o que permite contar com um bom nível de experiência e especialização, garantindo-se, assim, a qualidade e a fiabilidade destas perícias perante a justiça;

b) A existência de um serviço de perícias urgentes, on call, a funcionar 24 sobre 24 horas, o que permite responder em qualquer momento às solicitações feitas ao INML, com a realização precoce da avaliação médico-legal para exame físico 
e colheita de vestígios suscetíveis de se perderem com o tempo. Note-se que se verificam limitações no funcionamento destes serviços nas zonas não servidas diretamente pelas delegações do INML, mas os protocolos atualmente existentes entre os diversos serviços intervenientes são suficientemente ágeis para permitir ultrapassar estas limitações;

c) A existência de um modelo nacional de relatório pericial, o que além de orientar o perito na elaboração do seu relatório, garante uma estrutura uniforme do mesmo, e promove a descrição pormenorizada dos achados, evitando, desta forma, a perda de informação; por outro lado, é fundamental para a harmonização das práticas a nível nacional;

d) As auditorias internas regulares aos relatórios médico-legais, promovendo-se, assim, a qualidade dos mesmos.

Não se identificaram como pontos fortes a existência de guidelines nacionais para os procedimentos forenses (Magalhães e col., 2011), nem os protocolos celebrados entre diversas entidades intervenientes, por o estudo estar limitado ao ano de 2008 e estes factos serem posteriores, mas estes devem ser, na verdade, referidos também como pontos fortes. Acrescem, ainda, as múltiplas ações de formação sobre o tema, abrangendo profissionais de diferentes áreas de formação, implicados na intervenção deste tipo de casos, e que mais recentemente têm vindo a ser disponibilizadas em Portugal.

Como pontos fracos, podemos considerar os seguintes aspetos:

a) $\mathrm{O}$ atraso na revelação/denúncia dos casos, o que inviabiliza muitos estudos de ADN, pelo que importa investir em campanhas de informação da população em geral e das crianças em particular mas, também, na formação especializada dos técnicos que trabalham com crianças e adolescentes;

b) A reduzida solicitação de exames toxicológicos, sendo certos que muitos casos de agressões sexuais estão associados a intoxicação das vítimas. Assim, estes deverão ser solicitados a todas as crianças com (Harper, 2011; Oral e col, 2011a): (a) menos de 2 anos de idade; (b) lesões físicas graves; (c) desorientação; (d) amnésia para eventos recentes; (e) história de violência doméstica; (f) história de prisão efetiva de um dos cuidadores; (g) história de abuso de substâncias tóxicas por parte destes. Os resultados destes exames podem constituir mais um elemento, que por si só não provando a ocorrência do crime, podem, no contexto do abuso sexual, tornar a prova mais consistente e robusta e, desta forma, contribuir para uma decisão judicial mais justa; 
c) A reduzida solicitação de exames microbiológicos, sendo que a literatura refere que estes deverão ser solicitados, de forma sistemática, a adolescentes e a crianças pré-púberes sempre que (Oral e col., 2011b; Botash e col., 2005; Workowski \& Berman, 2010): (a) haja história e/ou sintomas/sinais de infeções sexualmente transmissíveis (IST); (b) a agressão tenha sido perpetrada por múltiplos indivíduos; (c) o agressor seja desconhecido; (d) haja história ou suspeita do agressor estar infetado por IST; (e) o agressor pertença a um grupo de risco (e.g., usuário de drogas de abuso); (f) a comunidade tenha uma elevada prevalência da doença; (g) seja solicitado pela vítima ou acompanhantes. O diagnóstico das IST é fundamental para o diagnóstico médico-legal, principalmente, em crianças com idade inferior a 14 anos ou sem atividade sexual consentida, pois constituem indicadores sugestivos (Adams, 2008) e, por alguns autores (Oral e col., 2011b, Workowski \& Berman, 2010; De Jong, 2009; Hammerschlag \& Guillen, 2010), até diagnósticos de abuso sexual, dependendo do agente etiológico em questão;

d) A reduzida solicitação de entrevista forense que, como atrás referido, deverá ser requerida de forma sistemática, sendo fundamental na valoração do relato da criança (Peixoto e col., 2011; Peixoto, Ribeiro, 2010), o qual por vezes constitui a única prova do abuso e que, como se demonstrou, constitui um dos fatores com grande impacto na decisão judicial;

e) O número reduzido dos especialistas em medicina legal, impossibilitando a implementação de um serviço de perícias urgentes em mais pontos do país, levando a que em algumas situações a colheita de vestígios seja efetuada por profissionais não forenses (Ribeiro e col., 2011).

Para que a intervenção médico-legal e forense neste tipo de casos seja cada vez mais atempada e correta, com o estabelecimento de um diagnóstico médico-legal seguro, que parta da interpretação de todos os elementos disponíveis à luz dos conhecimentos científicos atuais, será fundamental que se continue a providenciar no sentido de:

a) Estes exames serem feitos por especialistas de medicina legal particularmente vocacionados para esta área;

b) Sempre que possível, estes exames contarem com a presença de dois médicos;

c) Os relatórios médico-legais serem, se não elaborados por dois médicos, pelo menos revistos por um segundo médico; 
45 impacto da perícia médico-legal na decisão judicial nos casos de abuso sexual de crianças. Estudo preliminar

d) Existirem checklists a serem utilizadas pelos peritos durante a realização destes exames, principalmente nas perícias urgentes, designadamente: (i) material para a realização do exame; (ii) procedimentos gerais da avaliação; (iii) passos da observação, fotodocumentação e colheita de vestígios;

e) Atualizar o equipamento dos kits para exame;

f) Os relatórios médico-legais obedecerem sempre às normas definidas para a sua elaboração;

g) O modelo de relatório ser regularmente atualizado, tendo em conta a evolução científica relativa ao tema e a sua adequação à realidade nacional;

h) Se realizarem, regularmente, avaliações aos relatório elaborados;

i) Serem solicitados exames toxicológicos e microbiológicos a todos os casos incluídos nos critérios acima enunciados;

j) Serem efetuadas entrevistas forenses por profissionais especializados a todas as vítimas com idade inferior a 18 anos;

k) Serem desenvolvidos mais estudos científicos sobre o tema, principalmente no que diz respeito: (i) à interpretação das lesões e sequelas; (ii) aos exames genéticos, toxicológicos e microbiológicos; (iii) às decisões judiciais, cujas amostragens necessitam de uma maior dimensão do que a conseguida no presente trabalho;

i) Ser promovida e disponibilizada mais formação a todos quantos trabalham com crianças e adolescentes;

m) Serem promovidos mais protocolos que agilizem a articulação dos diferentes profissionais e instituições a nível da intervenção que, nestes casos, é obrigatoriamente multidisciplinar.

\section{CONCLUSÕES}

A análise dos casos alegados de crimes de natureza sexual revelou que:

1) Na maioria dos aspetos, os resultados obtidos são sobreponíveis aos publicados na literatura nacional e estrangeira, verificando-se, contudo, uma maior taxa de abuso intrafamiliar; 
2) As decisões judiciais que foram objeto de estudo correspondem a $18 \%$ dos alegados casos de crime sexual em crianças com idade inferior a 18 anos, presentes a exame médico-legal nos serviços médico-legais da região norte de Portugal entre 2004 e 2008;

3) Foram sujeitos a arquivamento ou suspensão provisória do processo, 69\% dos casos denunciados ao Ministério Público;

4) Foram acusados e julgados $31 \%$ dos referidos casos;

5) Destes, $86 \%$ foram condenados (27\% do total de casos em estudo);

6) Dos condenados, a pena foi de prisão efetiva ou suspensa em $49 \%$ e $42.8 \%$ dos casos, respetivamente;

7) O tempo médio da pena foi de 4 anos;

8) O tempo médio decorrido entre o exame médico-legal e a decisão judicial final foi de 11 meses nos casos arquivados ou provisoriamente suspensos e de 22 meses nos casos julgados;

9) As condenações apresentaram uma relação estatisticamente significativa com:

a) a idade da vítima;

b) a revelação do crime pela própria vítima;

c) a presença de testemunhas oculares das práticas abusivas;

d) as práticas abusivas reiteradas;

e) a existência de perfil genético do suspeito no corpo e/ou roupas da vítima;

f) as conclusões médico-legais diagnósticas ou sugestivas de contacto sexual.

Estes últimos resultados vão no sentido de que a perícia médico-legal e forense contribui de forma significativa para a decisão judicial.

Ainda quanto à perícia médico-legal, identificaram-se: como pontos fortes, o facto de estas serem sempre feitas por peritos forenses do INML, com um serviço on call a funcionar 24 sobre 24 horas, contando com um modelo nacional de relatório pericial; como pontos fracos, o atraso na revelação/ denúncia dos casos, o que inviabiliza muitos estudos de $\mathrm{ADN}$, e a reduzida solicitação de exames toxicológicos, microbiológicos e de entrevista forense.

Este estudo deixou ainda muitas questões em aberto, tornando-se evidente a necessidade de se avançar para um estudo mais aprofundado sobre esta 
problemática, com uma amostra mais alargada e mais atualizada de casos, tendo em vista o melhor conhecimento da realidade judicial para que se possa adequar cada vez mais a atividade pericial a uma boa administração da Justiça, tanto do ponto de vista criminal como da proteção da criança.

Figura 1. Decisões judiciais

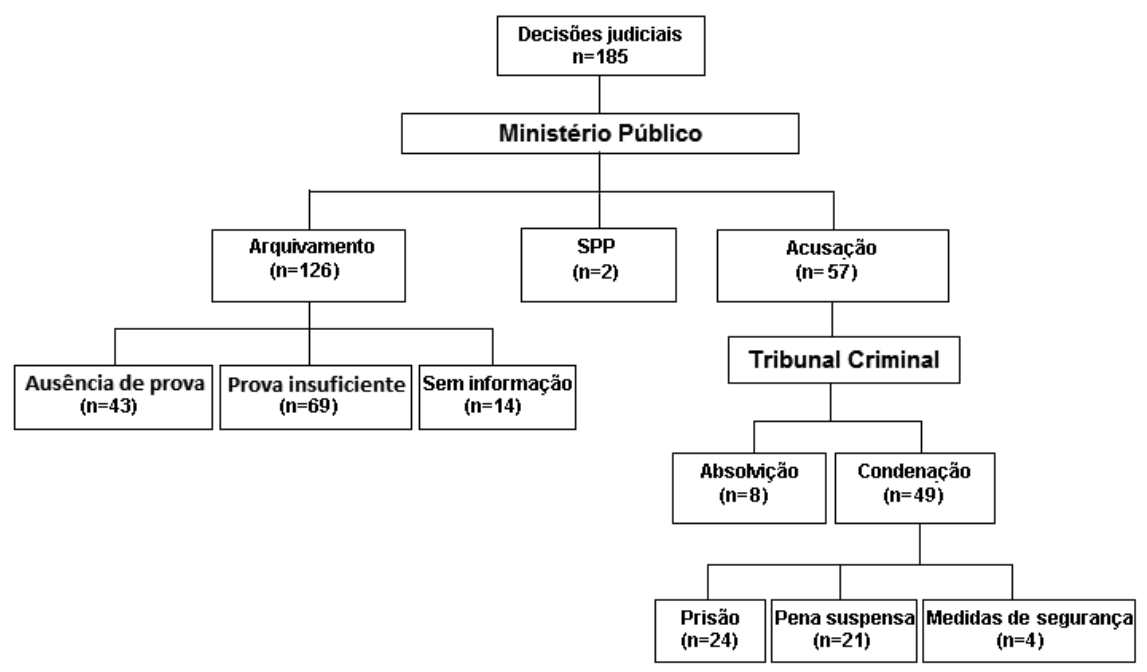

Tabela 1. Caracterização da vítima $(n=185)$

\begin{tabular}{|c|c|c|c|c|}
\hline & & $\begin{array}{c}\mathrm{CC}(\mathrm{n}=49) \\
\mathrm{n}(\%)\end{array}$ & $\begin{array}{c}\mathrm{CNC}(\mathrm{n}=136) \\
\mathrm{n}(\%)\end{array}$ & $\mathrm{r}$ \\
\hline \multirow{2}{*}{ Género } & Feminino & $36(73.5)$ & $109(80.1)$ & \multirow{2}{*}{0.33} \\
\hline & Masculino & $13(26.5)$ & $27(19.9)$ & \\
\hline \multirow{4}{*}{$\begin{array}{l}\text { Idade } \\
\text { (anos) }\end{array}$} & Média & 10.52 & 9.57 & \multirow{4}{*}{0.12} \\
\hline & Min. & 0.35 & 0.63 & \\
\hline & Max. & 16.64 & 16.37 & \\
\hline & SD & 3.46 & 4.20 & \\
\hline \multirow{3}{*}{ Atividade } & Nenhuma & $7(14.3)$ & $42(30.9)$ & \multirow{3}{*}{0.02} \\
\hline & Estudante & $40(81.6)$ & $88(64.7)$ & \\
\hline & Sem informação & $2(4.1)$ & $6(4.4)$ & \\
\hline \multirow{6}{*}{$\begin{array}{l}\text { Tipo de } \\
\text { família }\end{array}$} & Nuclear & $21(42.9)$ & $49(36.0)$ & \multirow{6}{*}{0.83} \\
\hline & Monoparental & $6(12.2)$ & $24(17.6)$ & \\
\hline & Recombinada & $5(10.2)$ & $10(7.4)$ & \\
\hline & Alargada & $7(14.3)$ & $18(13.2)$ & \\
\hline & $\begin{array}{l}\text { Instituição/Família de } \\
\text { acolhimento }\end{array}$ & $2(4.1)$ & $7(5.2)$ & \\
\hline & Sem informação & $8(16.3)$ & $28(20.6)$ & \\
\hline
\end{tabular}


Tabela 2. Caracterização do alegado agressor $(n=185)$

\begin{tabular}{ccccc} 
& & CC (n=49) & CNC (n=136) & r \\
& & $\mathbf{n}(\%)$ & $135(99.3)$ & \multirow{2}{*}{$0.74^{*}$} \\
\hline \multirow{2}{*}{ Género } & Masculino & $49(100)$ & $1(0.7)$ & \\
& Feminino & 0 & $11(8.1)$ & \\
& $13-17$ & $5(10.2)$ & $17(12.5)$ & \\
Idade (anos) & $18-30$ & $6(12.2)$ & $10(7.4)$ & 0.37 \\
& $31-40$ & $12(24.5)$ & $7(5.1)$ & \\
& $41-50$ & $5(10.2)$ & $6(4.4)$ & \\
& $51-74$ & $4(8.2)$ & $85(62.5)$ & \\
Atividade & Sem informação & $17(34.7)$ & $19(14.0)$ & \\
& Profissão & $15(30.6)$ & $3(2.2)$ & 0.94 \\
& Estudante & $2(4.1)$ & $8(5.9)$ & \\
Relação com a & Desempregado & $5(10.2)$ & $106(77.9)$ & \\
vítima & Sem informação & $27(55.1)$ & $24(17.6)$ & \\
& Desconhecido & $3(6.1)$ & $45(33.1)$ & 0.13 \\
\hline
\end{tabular}

* Fisher exact test

Tabela 3. Caracterização da primeira suspeita $(n=185)$

\begin{tabular}{ccccc} 
& & $\mathrm{CC}(\mathrm{n}=49)$ & $\mathrm{CNC}(\mathrm{n}=136)$ & $\mathrm{r}$ \\
\cline { 3 - 5 } & & $\mathrm{n}(\%)$ & $44(32.4)$ & \\
$\begin{array}{c}\text { Sinalização e/ou } \\
\text { Denúnica }\end{array}$ & Familiares & $15(30.6)$ & $32(23.5)$ & 0.57 \\
& Outras pessoas & $14(28.6)$ & $60(44.1)$ & \\
\hline \multirow{4}{*}{ Fonte da suspeita } & Sem informação & $20(40.8)$ & $26(19.1)$ & \\
& Observação de sinais e & $3(6.1)$ & $43(31.6)$ & 0.03 \\
& Sintomas sugestivos & $21(42.9)$ & $11(8.1)$ & \\
& Revelação pela vítima & $8(16.3)$ & $56(41.2)$ & \\
\hline \multirow{2}{*}{ Instituição à qual } & Testemunha ocular & $17(34.7)$ & $23(16.9)$ & \\
foi & Sem informação & $9(18.4)$ & $13(9.6)$ & \\
comunicada a & Serviços de saúde & $7(14.3)$ & $11(8.1)$ & $0.95 *$ \\
suspeita & Polícia & $5(10.2)$ & $3(2.2)$ & \\
& CPCJ & $1(2.0)$ & $86(63.2)$ & \\
\hline
\end{tabular}

* Em 3 células (37.5\%), os valores esperados são inferiores a 5. 
49 impacto da perícia médico-legal na decisão judicial nos casos de abuso sexual de crianças. Estudo preliminar

Tabela 4. Caracterização da alegada agressão $(n=185)$

\begin{tabular}{|c|c|c|c|c|}
\hline & & $\begin{array}{c}\mathrm{CC}(\mathrm{n}=49) \\
\mathrm{n}(\%)\end{array}$ & $\begin{array}{c}\mathrm{CNC}(\mathrm{n}=136) \\
\mathrm{n}(\%)\end{array}$ & $\mathrm{r}$ \\
\hline \multirow{7}{*}{ Tipo } & Carícias sexualmente explícitas & $19(38.8)$ & $43(31.6)$ & \multirow{7}{*}{$0.66^{*}$} \\
\hline & $\begin{array}{c}\text { Tentativa de penetração oral, anal } \\
\text { ou vaginal }\end{array}$ & $4(8.2)$ & $13(9.6)$ & \\
\hline & Penetração oral & $0(0)$ & $2(1.5)$ & \\
\hline & Penetração anal & $8(16.3)$ & $12(8.8)$ & \\
\hline & Penetração vaginal & $5(10.2)$ & $17(12.5)$ & \\
\hline & Penetração anal e/ou vaginal & $4(8.2)$ & $4(2.9)$ & \\
\hline & Sem informação & $9(18.4)$ & $45(33.1)$ & \\
\hline \multirow{3}{*}{ Local } & Casa da vítima e/ou agressor & $20(40.8)$ & $64(47.1)$ & \multirow{3}{*}{0.156} \\
\hline & Local isolado & $16(32.7)$ & $29(21.3)$ & \\
\hline & Sem informação & $13(26.5)$ & $43(31.6)$ & \\
\hline \multirow{4}{*}{ Frequência } & Única & $12(24.5)$ & $50(36.8)$ & \multirow{4}{*}{$0.004 *$} \\
\hline & Esporádica & $10(20.4)$ & $8(5.9)$ & \\
\hline & Regular & $9(18.4)$ & $21(15.4)$ & \\
\hline & Sem informação & $18(36.7)$ & $57(41.9)$ & \\
\hline \multirow{4}{*}{ Circunstâncias } & Ameaças verbais & $13(26.5)$ & $11(8.1)$ & \multirow{4}{*}{0.14} \\
\hline & Violência física & $11(22.5)$ & $15(11.0)$ & \\
\hline & Outras & $8(16.3)$ & $21(15.4)$ & \\
\hline & Sem informação & $17(34.7)$ & $89(65.4)$ & \\
\hline
\end{tabular}

* O valor de $r$ corresponde aos grupos "carícias sexualmente explícitas",

"tentativa de penetração" e "penetração"

Tabela 5. Caracterização do exame médico-legal $(n=185)$

\begin{tabular}{|c|c|c|c|c|}
\hline & & \\
\hline & & $\begin{array}{c}\mathrm{CC}(\mathrm{n}=49) \\
\mathrm{n}(\%)\end{array}$ & $\begin{array}{c}\mathrm{CNC}(\mathrm{n}=136) \\
\mathrm{n}(\%)\end{array}$ & $\mathrm{r}$ \\
\hline \multirow{2}{*}{$\begin{array}{l}\text { Horas entre o alegado } \\
\text { crime e o exame } \\
\text { médico-legal }\end{array}$} & $\leq 72$ horas & $11(22.4)$ & $34(25.0)$ & \multirow[b]{2}{*}{0.72} \\
\hline & $>72$ horas & $38(77.6)$ & $102(75)$ & \\
\hline \multirow{3}{*}{ Lesões e sequelas } & Sugestivas & $8(16.3)$ & $16(11.8)$ & \multirow{3}{*}{0.51} \\
\hline & Inespecíficas & $7(14.3)$ & $28(20.6)$ & \\
\hline & $\begin{array}{c}\text { Ausência de lesões/ } \\
\text { sequelas }\end{array}$ & $34(69.4)$ & $92(67.6)$ & \\
\hline \multirow{3}{*}{ Genética } & Positivo & $5(10.2)$ & $2(1.5)$ & \multirow{3}{*}{$0.03 *$} \\
\hline & Negativo & $5(10.2)$ & $22(16.2)$ & \\
\hline & Não realizado & $39(79.6)$ & $112(82.4)$ & \\
\hline \multirow{2}{*}{ Toxicologia } & Realizado & $1(2.0)$ & $4(2.9)$ & \multirow{2}{*}{ - } \\
\hline & Não realizado & $48(98.0)$ & $132(97.1)$ & \\
\hline \multirow{2}{*}{ Microbiologia } & Realizado & $8(16.3)$ & $16(11.8)$ & \multirow{2}{*}{ - } \\
\hline & Não realizado & $41(83.7)$ & $120(88.2)$ & \\
\hline \multirow{2}{*}{ Entrevista forense } & Realizada & $28(57.1)$ & $69(50.7)$ & \multirow{2}{*}{$0.44^{*}$} \\
\hline & Não realizada & $21(42.9)$ & $67(49.3)$ & \\
\hline
\end{tabular}

* Fisher exact test 
Tabela 6. Caracterização das conclusões médico-legais $(\mathbf{n}=185)$

\begin{tabular}{lccc}
\cline { 2 - 3 } & $\mathrm{CC}(\mathrm{n}=49)$ & $\mathrm{CNC}(\mathrm{n}=136)$ & $\mathrm{r}$ \\
\hline Diagnóstico & $\mathrm{n}(\%)$ & $\mathrm{n}(\%)$ & \\
Sugestivo & $4(8.2)$ & $3(2.2)$ & \\
Inespecífico & $8(16.3)$ & $5(3.7)$ & 0.002 \\
\hline
\end{tabular}

\section{REFERÊNCIAS BIBLIOGRÁFICAS}

Adams JA, Harper K, Knudson S, Revilla J. Examination findings in legally confirmed child sexual abuse: it's normal to be normal. Pediatrics, 1994; 94:310-7.

Adams JA. Guidelines for medical care of children evaluated for suspected sexual abuse: an update for 2008. Curr Opin Obstet Gynecol, 2008; 20:435-41.

Becker J. Offenders: characteristics and treatment. The future of children. Sexual Abuse of Children, 1994; 4:176-97.

Botash AS, Galloway AE, Booth T e col. Continuing medical education in child sexual abuse: cognitive gains but not expertise. Arch Pediatr Adolesc Med, 2005; 159:561-6.

Bradshaw T, Marks A. Beyond a reasonable doubt: Factors that influence the legal disposition of child sexual abuse cases. Crime \& Delinquency, 1990; 36:276-85.

Briere J, Elliott DM. Prevalence and psychological sequelae of self-reported childhood physical and sexual abuse in a general population sample of men and women. Child Abuse Negl, 2003; 27:1205-22.

Christian CW, Lavelle JM, De Jong AR e col. Forensic evidence findings in prepubertal victims of sexual assault. Pediatrics, 2000; 106:100-4.

Cross TP, Walsh WA, Simone M, Jones LM. Prosecution of child abuse: a meta-analysis of rates of criminal justice decisions. Trauma Violence Abuse, 2003; 4:323-40.

Cross TP, Whitcomb D, De Vos E. Criminal justice outcomes of prosecution of child sexual abuse: a case flow analysis. Child Abuse Negl, 1995; 19:1431-42.

Csorba R, Aranyosi J, Borsos A e col. Characteristics of female child sexual abuse in Hungary between 1986 and 2001: a longitudinal, prospective study. Eur J Obstet Gynecol Reprod Biol, 2005; 120:217-21.

De Jong A, Rose M. Legal proof of child sexual abuse in the absence of physical evidence. Pediatrics, 1991; 88:506-11.

De Jong A. Sexually transmitted infections in child sexual abuse. In: Reece R, Christian C, editors. Child abuse: Medical diagnosis \& management. $3^{\text {rd }}$ edition. Philadelphia: AAP publications; 2009. p. 343-76.

De Jong AR, Hervada AR, Emmett GA. Epidemiologic variations in childhood sexual abuse. Child Abuse Negl, 1983; 7:155-62.

De Jong, A. Impact of child sexual abuse medical examinations on the dependency and criminal systems. Child Abuse Negl, 1998; 22(6): 645-52.

De Munnynck K, De Houwer L, Bronselaer K e col. Medico-legal approach to sexual assault victims: the Belgian situation. J Clin Forensic Med, 2006; 13:211-4.

Faller-marquardt M, Ropohl D, Pollak S. Excoriations and contusions of the skin as artefacts in fictitious sexual offences. J Clin Forensic Med, 1995; 2:129-35. 
51 impacto da perícia médico-legal na decisão judicial nos casos de abuso sexual de crianças. Estudo preliminar

Finkel M. Sexual abuse: the medical examination. In: Giardino A, Alexander R, editors. Child maltreatment. A clinical guide and reference. St. Louis: GW Medical; 2005. p. 253-88.

Finkelhor D. Current information on the scope and nature of child sexual abuse. Future Child, 1994; 4:31-53.

Fischer DG, McDonald WL. Characteristics of intrafamilial and extrafamilial child sexual abuse. Child Abuse Negl, 1998; 22:915-29.

Goodman GS, Taub EP, Jones DP e col. Testifying in criminal court: emotional effects on child sexual assault victims. Monogr Soc Res Child Dev, 1992; 57:1-142.

Goodman-brown T, Edelstein R, Goodman G e col. Why children tell: a model of children's disclosure of sexual abuse. Child Abuse Negl, 2003; 27:525-40.

Hammerschlag MR, Guillen CD. Medical and legal implications of testing for sexually transmitted infections in children. Clin Microbiol Rev, 2010; 23:493-506.

Harper N. Drug-facilitated sexual assault, In: Jenny C, editor. Child abuse and neglect. Diagnosis, treatment, and evidence. St Louis, Missouri: Elsevier Saunders; 2011. p. 118-26.

Heger A, Ticson L, Velasquez O, Bernier R. Children referred for possible sexual abuse: medical findings in 2384 children. Child Abuse Negl, 2002; 26:645-59.

Hershkowitz I. A case study of child sexual false allegation. Child Abuse Negl, 2001; 25:1397-411.

Ingemann-Hansen O, Brink O, Sabroe S e col. Legal aspects of sexual violence-does forensic evidence make a difference? Forensic Sci Int, 2008;; 180:98-104.

Jardim P, Magalhães T. Indicadores Físicos e Biológicos de Abuso. In: Magalhães, ed. Abuso de crianças e jovens. Da suspeita ao diagnóstico, Lisboa: Lidel; 2010. p. 109-18.

London K, Bruck M, Ceci S, Shuman D. Disclosure of child sexual abuse. What does the research tell us about the ways that children tell? Psychology, Public Policy, and Law, 2005; 11:194-226.

Magalhães T, Carneiro de Sousa MJ, Gomes da Silva e col. Child sexual abuse: a preliminary study. J Clin Forensic Med, 1998; 5:176-82.

Magalhães T, Ribeiro C. [Interviewing victims of sexual crimes]. Acta Med Port, 2007; 20:439-45.

Magalhães T, Ribeiro CS, Jardim P, Vieira DN. [Forensic procedures for interview physical exam and evidence collection in children and young people victims of physical and/ or sexual abuse]. Acta Med Port, 2011; 24:339-48.

Magalhães T, Taveira F, Jardim P e col. Sexual abuse of children. A comparative study of intra and extra-familial cases. J Forensic Leg Med, 2009; 16:455-9.

Martone M, Jaudes PK, Cavins MK. Criminal prosecution of child sexual abuse cases. Child Abuse Negl, 1996; 20:457-64.

McGregor MJ, Le G, Marion SA, Wiebe E. Examination for sexual assault: is the documentation of physical injury associated with the laying of charges? A retrospective cohort study. CMAJ, 1999; 160:1565-9.

Muram D, Speck P, Gold S. Genital abnormalities in female siblings and friends of child victims of sexual abuse. Child Abuse Negl, 1991; 15:105-10.

Myers JE. A call for forensically relevant research. Child Abuse Negl, 1993; 17:573-9.

Myers JE. Adjudication of child sexual abuse cases. Future Child, 1994; 4:84-101.

Nagel D, Putnam F, Noll J. Disclosure patterns of sexual abuse and psychological functioning at 11-year follow up. Child Abuse Negl, 1996; 21:137-47. 
Oral R, Bayman L, Assad A e col. Illicit drug exposure in patients evaluated for alleged child abuse and neglect. Pediatr Emerg Care, 2011; 27:490-5 (a).

Oral R, Jardim P, Magalhães T. Sexually transmitted infections in child sexual abuse/ assault: diagnosis, forensic significance, and treatment. In: Magalhães T, ed. Abuse \& Neglect, Series 1 - To improve the management of child abuse and neglect. Maia: SPECAN; 2011. p.161-74 (b).

Palusci VJ, Cox EO, Shatz EM,Schultze JM. Urgent medical assessment after child sexual abuse. Child Abuse Negl, 2006; 30:367-80.

Patterson D, Campbell R. A comparative study of the prosecution of childhood sexual abuse cases: the contributory role of pediatric Forensic Nurse Examiner (FNE) programs. J Forensic Nurs, 2009; 5:38-45.

Peixoto C, Ribeiro C, Lamb M. Forensic interview protocol in child sexual abuse. Why and what for? In: Magalhães T, ed. Abuse \& Neglect, Series 1 - To improve the management of child abuse and neglect. Maia: SPECAN; 2011. p. 133-59.

Peixoto C, Ribeiro C. Indicadores psicológicos de abuso. In: Magalhães, ed. Abuso de crianças e jovens. Da suspeita ao diagnóstico, Lisboa: Lidel; 2010. P. 39-49.

Pereda N, Guilera G, Forns M, Gomez-Benito J. The international epidemiology of child sexual abuse: a continuation of Finkelhor (1994). Child Abuse Negl, 2009; 33:331-42 (a).

Pereda N, Guilera G, Forns M, Gomez-Benito J. The prevalence of child sexual abuse in community and student samples: a meta-analysis. Clin Psychol Rev, 2009; 29:328-338 (b).

Pillai M. Genital findings in prepubertal girls: what can be concluded from an examination? J Pediatr Adolesc Gynecol, 2008; 21:177-85.

Pinto da Costa D, Magalhães T, Matos E e col. Sexual offences. Journal of Clinical Forensic Medicine, 1998; 5:12.

Ribeiro C. A criança na Justiça. Trajectórias e significados do processo judicial de crianças vítimas de abuso sexual intrafamiliar. Coimbra: Almedina, 2009.

Ribeiro CS, Magalhães T. Aspectos epidemiológicos do abuso. In: Magalhães, ed. Abuso de crianças e jovens. Da suspeita ao diagnóstico, Lisboa: Lidel; 2010. p. 23-9.

Ribeiro CS, Oral R, Carmo e col. Management of child abuse and neglect in Portugal. A comprehensive and critical review. In: Magalhães T, ed. Abuse \& Neglect, Series 1 - To improve the management of child abuse and neglect. Maia: SPECAN; 2011. p. 11-30.

Spears FM, Brown BW, Atkinson EN. The effect of incomplete knowledge of parameter values on single- and multiple-stage designs for logistic regression. Biometrics, 1997; 53:1-10.

Spears J, Spohn C. The genuine victim and prosecutors' charging decisions in sexual assault cases. American Journal of Criminal Justice, 1996; 20:183-205.

Stewart D. Physical Findings in children and adolescents experiencing sexual abuse or assault In: Jenny C (editor). Child abuse and neglect. Diagnosis, treatment, and evidence. St Louis: Elsevier Saunders; 2011. p. 82-92.

Sugue-Castillo M. Legal outcomes of sexually abused children evaluated at the Philippine General Hospital Child Protection Unit. Child Abuse Negl, 2009; 33:193-202.

Swanston HY, Plunkett AM, O'Toole BI e col. Nine years after child sexual abuse. Child Abuse Negl, 2003; 27:967-84.

Taveira F, Frazão S, Dias R e col. [Intra and extra-familiar sexual abuse]. Acta Med Port, 2009; 22:759-66. 
Tjaden PG, Thoennes N. Predictors of legal intervention in child maltreatment cases. Child Abuse Negl, 1992; 16:807-21.

Wiley J, Sugar N, Fine D, Eckert LO. Legal outcomes of sexual assault. Am J Obstet Gynecol, 2003; 188:1638-41.

Workowski K, Berman S. Sexually transmitted diseases treatment guidelines. MMWR Recomm Rep, 2010; 59:1-110.

WHO - World Health Organization. Child sexual abuse: A silent health emergency. Regional Office for Africa. [documento online] 2004; [atualizado em 06.11.2011]; AFR/RC54/15 Rev.1. Disponível em: http://www.who.int/iris/handle/123456789/1878.

WHO - World Health Organization. Guidelines for medico-legal care for victims of sexual violence. Geneva: WHO Library Cataloguing-in-Publication Data; 2003.

Resumo: 0 impacto da perícia médico-legal para a decisão judicial nos casos de abuso sexual de crianças. Estudo preliminar

$\mathrm{Na}$ investigação científica sobre o abuso sexual, sobretudo na perspetiva médico-legal e forense, deparamo-nos com múltiplas dificuldades, designadamente a nível dos conceitos usados e seus significados, e a nível da amostragem das populações. 0 objetivo geral deste estudo é contribuir para melhor caracterizar, em termos médico-legais e forenses, os abusos sexuais contra crianças em Portugal e baseou-se na análise de relatórios periciais de alegados crimes de natureza sexual, contra vítimas com idade inferior a 18 anos, submetidas a exame médico-legal nos serviços médico-legais do norte de Portugal, entre 2004 e 2008, para os quais se obteve as decisões judiciais $(n=185)$, comparando-se os casos que foram condenados com os que não foram. Os resultados revelaram que apenas $30.8 \%$ dos casos foram acusados e julgados, sendo que destes, $86 \%$ foram condenados. 0 tempo médio decorrido entre o exame médico-legal e a decisão judicial final foi de 11 meses nos casos arquivados ou provisoriamente suspensos e de 22 meses nos casos acusados e julgados. As condenações apresentam uma relação estatisticamente significativa com $(p<0.05)$ : (a) vítimas em idade escolar; (b) a revelação do abuso pelas vítimas; (c) a existência de testemunhas oculares das práticas abusivas; (d) a reiteração dos abusos; (e) a deteção do perfil genético do suspeito no corpo e/ou roupas da vítima; (f) as conclusões médico-legais diagnósticas ou sugestivas de contacto sexual. Daqui se infere que a perícia médico-legal e forense contribui de forma significativa para a decisão judicial.

Palavras-chave: Abuso sexual; crianças; perícia médico-legal; decisão judicial.

Summary: The impact of the forensic evaluation for the judicial decision in cases of children sexual abuse. Preliminary study

In the field of scientific research on sexual abuse, particularly from the forensic perspective, we often come across several hurdles, namely concerning the terms used and their specific meaning, as well as the sampling of the population studied. The objective of this study is to better characterize child sexual abuse in Portugal, from a forensic perspective. An analysis on the forensic examination reports of alleged sexual crimes against victims under 18 years of age was performed, concerning cases from the northern forensic services between 2004 
and 2008, for which we also obtained the correspondent legal outcomes $(n=185)$, which allowed the comparison between convicted and non-convicted cases. The results revealed that only $30.8 \%$ were charged and trialed, and that in $86 \%$ of such cases the abusers were convicted. The average time span between the forensic examination and the final judicial decision was 11 months in non-prosecuted cases and 22 months in prosecuted cases. Convictions presented a significant statistic correlation $(p<0.05)$ with: (a) victims in school age, (b) the disclosure of the abuse by the victims, (c) the availability of eyewitnesses accounts, (d) the repetition of the abuses, (e) the detection of the suspect's genetic profile on the body and/or clothes of the victim, ( $f$ ) the reference to diagnostic or suggestive sexual contact in medico-legal conclusions. It therefore follows that medico-legal and forensic intervention significantly contributes to the judicial decision.

Key-words: Sexual abuse; child; forensic expertise; judicial decision.

Résumé: Impact de l'expertise médico-légale sur la décision légale en cas d'abus sexuel chez l'enfant. Étude préliminaire.

Quand nous effectuons une recherche scientifique sur les abus sexuels, en particulier dans la perspective médico-légale, nous sommes confrontés à des nombreuses difficultés, aussi bien au niveau des concepts utilisés et de leur signification ainsi qu'à l'échantillonnage des populations. L'objectif de cette étude est de contribuer à mieux caractériser, en termes médico-légaux, les abus sexuels chez les enfants au Portugal. Il s'appui sur l'analyse des rapports médico-légaux relatifs aux allégations de crimes sexuels par rapport aux victimes âgées de moins de 18 ans. Les victimes ont été soumises à un examen médico-légal dans les services médico-légaux du nord du Portugal, entre 2004 et 2008, analysant les cas où les décisions judiciaires ont été conclusives $(n=185)$. Les auteurs ont comparé les cas qui ont aboutis en accusation des agresseurs para rapport aux cas sans accusation. Les résultats ont révélé que seulement $30.8 \%$ des cas ont été inculpés et jugés et que $86 \%$ des agresseurs ont été condamnés. Le temps moyen écoulé entre l'examen médico-légal et la décision judiciaire finale était de 11 mois dans les cas déposés ou provisoirement suspendue et de 22 mois en cas de poursuite et de jugement. Les condamnations montrent une relation statistique significative avec $(p<0.05)$ : (a) les victimes d'âge scolaire, (b) la divulgation de l'abus par les victimes, (c) l'existence de témoins oculaires, (d) la répétition des abus, (e) la détection du profil génétique du suspect aussi bien sur le corps ainsi que dans les vêtements de la victime, (f) les conclusions médico-légales de diagnostic ou suggestives de contact sexuel. Il s'ensuit donc que l'expertise médico-légale contribue de manière significative pour la décision légale.

Mots-clés: Abus sexuel; enfant; expertise médico-légale; décision légale.

\section{Pedido de separatas:}

PATRÍCIA JARDIM

patricia.j.a.jardim@gmail.com 